\title{
Value of Renal Diffusion-Weighted MRI as a Non-Invasive Predictor of Renal Dysfunction
}

\author{
SHERIF F. ABD EL-RAHMAN, M.D.* and AHMED M. SHOMAN, M.D.** \\ The Departments of Radiology* and Urology**, Faculty of Medicine, Cairo University, Egypt
}

\begin{abstract}
Background: Chonic kidney disease (CKD) is a widespread health trouble. Laboratory tests and differant radiological procedures are helpful for the assesing tje kidney anatomical cganges and function. Diffusion weighted (DW) MRI with the apparent diffusion coefficent (ADC) are growing fields and numerous studies have tried to estimate their value in the assessment of the renal parenchyma.
\end{abstract}

Aim of Work: To assess relationship between kidney laboratory markers and values of MR apparent diffusion cofficient (ADC) of the renal parenchyma.

Patients and Methods: A ratrosective study was made for 100 patients who were examined by DW-MRI (at 0 and $500 \mathrm{~s} / \mathrm{mm}^{2} b$-values) for different renal lesions along the year 2017, revealed 44 patients having renal dysfunction and 56 with normal kisney function. Among those 44, 30 patients were known to have CKD. The ADC values were measured for the renal parenchyma of each kidney \& compared withe those values of the control normal kidneys. Receicer operating characteristic (ROC) curve was made to specify the ADC cutoff value.

Results: Significantly lower average ADC values were noted in patients with renal dysfunction than those in patients having normal kidney function (1.69vs. $2.29\left(\mathrm{x} 10-\mathrm{mm}^{2} / \mathrm{s}\right)$ An inverse correlation between the ADC value and serum creatinine was statiscally significant $(r=0.778, p=0.002)$. The çut of ADC value for renal dysfunction was 2.0355 (x10$\mathrm{mm} / \mathrm{s}$ ).

Conclusion: Measured MRI ADC values can be a useful marker for prediction od renal parenchymal disease. Beside renal morphological assessment, MRI can give useful idea about the renal function though measuring the ADC values for total comoprehhensive renal assessment.

Key Words: Chronic kidney disease (CKD) - Apparent diffusion coefficent $(A D C)$ - Diffusion weighted $(D W)$.

\section{Introduction}

CHRONIC kidney disease (CKD) is a widespread health trouble with a prevalence of 150 per a million

Correspondence to: Dr. Sherif F. Abd El-Rahman, The Department of Radiology, Faculty of Medicine, Cairo University, Egypt population in developing countries [1]. Blood urea (BU), Serum creatinine (S-Cr), and the estimated glomerular filtration rate (eGFR) are helpful for the assessing the kidney function; but they are indirect measures for the assessment of the renal filtration and can be inaccurate. In addition they cannot assess the function of each single kidney [2].

Regarding those disadvantages of the serum laboratory markers, radiological imaging can play a role in evaluating the condition of the renal parenchyma. Ultrasonography (USG) and computed tomography $(\mathrm{CT})$ can provide valuable anatomical information but with no functional data. USG can describe changes in the echogenicity of the renal parenchyma, but it is operator dependent [3]

CT scan carries the risk of ionizing radiation exposure and requires iodinated contrast, which should be avoided in patients with renal impairment. Moreover, magnetic resonance imaging (MRI) is able to show the renal structure and evaluate the renal function without exposing the patient to ionizing radiation. MRI Functional techniques, like blood-oxygen-level-dependent (BOLD) imaging, diffusion weighted imaging (DWI), and contrast enhanced MRI study have potential role in renal function evaluation. Diffusion-weighted MRI (DW-MRI) is a safe non-invasive imaging modality to distinguish different tissues depending on the Brownian movement of the tissues water molecules [4].

Apparent diffusion coefficient (ADC) is a quantitative tool that can be measured from DWI which combines both effects of water diffusion and capillary perfusion. DW-MRI is a growing field and numerous studies have tried to estimate its value in the categorization of different focal kidney lesions [5-11] and assessment of the renal parenchyma [7,12-16] . 
The aim of our study is to evaluate the relationship between the measured renal parenchymal ADC values and the kidney function serum laboratory markers. In addition, to establish ADC cut-off value to suggest renal dysfunction.

\section{Patients and Methods}

This is a retrospective study performed in KasrAliny Hospital along the year 2017 after being approved by the institutional committee of ethics.

For focal renal lesions, DW-MRI was routinely done as part of our institutional protocol. Reviewing the patients who were examined by DW-MRI for evaluation of a renal focal lesion along 2017 was retrospective made, and showed that 100 patients (55 men, 45 women, with 47 years mean age, 2070 years age range), for whom DW imaging was done for both kidneys. Depending on the fact of having high $\mathrm{S}-\mathrm{Cr}>1.5 \mathrm{mg} / \mathrm{dl}$ and/or high $\mathrm{BU}>40$ $\mathrm{mg} / \mathrm{dl}$ renal dysfunction was clinically defined and the patients were classified [17]

44 patients were classified to have impaired renal function while 56 patients were with normal serum kidney markers. The mean serum creatinine level of the study group with renal dysfunction was $4.0 \mathrm{mg} / \mathrm{dl}$ (S Cr range $1.7-19 \mathrm{mg} / \mathrm{dl})$ and the mean blood urea level was $95 \mathrm{mg} / \mathrm{dl}$ (range 45 $200 \mathrm{mg} / \mathrm{dl}$ ). Out of those 44 patients having the laboratory evidence of renal dysfunction, $30 \mathrm{pa}-$ tients were previously diagnosed to have CKD, meanwhile the rest of the patients were recently discovered to have abnormal kidney function.

For the patients with CKD, the eGFR was calculated using MDRD method for creatinine clearance, with the estimated e-GFR was ranging between 14 and 34. All the clinical, laboratory and MRI data was collected.

\section{MRI examination:}

All the patients have been examined by MRI on a 1.5-Tesla MR scanner (Gyroscan Intera, Philips medical systems, Netherlands) equipped with a body/surface phased array coil, with the patient in supine position.

All sequences were respiratory triggered, in which the position of the diaphragm is periodically assessed by navigator echoes. We start with the conventional MRI sequences, including in-phase and opposed-phase axial T1 weighted gradient-echo sequence, (TR: $180 \mathrm{~ms}$, TE: $4.6 \mathrm{~ms} / 2.3 \mathrm{~ms}$, flip angle: $90^{\circ}$, field of view: $350 \times 275$ ), axial T2 weighted turbo spin-echo sequence with fat suppression (TR: 2,000ms, TE: $100 \mathrm{~ms}$, flip angle: $90^{\circ}$, field of view: $350 \times 275)$ and coronal T2 weighted half-Fourier single-shot turbo spin-echo sequence (HASTE) (TR: Infinite, TE: $120 \mathrm{~ms}$, flip angle: $90^{\circ}$, field of view: 350x275). Then, axial DW-MR imaging was performed using FS spin echo-echo planar imaging (SE-EPI) at 0,500 and $1000 \mathrm{~s} / \mathrm{mm}^{2} b$-values, applied in 3 orthogonal directions ( $\mathrm{x}, \mathrm{y}$, and $\mathrm{z}$ ).

Good quality images for DW and the ADC maps were obtained in all patients using the following parameters: 1600/62ms (TR/TE), 80degrees (flip angle), $7 \mathrm{~mm}$ (slice thickness), 0 (gap), 190x 115 (field of view), 94x192 (matrix), 2-5min (acquisition time).

\section{Image analysis \& ADC calculation:}

Using an attached workstation (Philips), the regions of interest (ROIs) were positioned on the examined kidneys, for quantitative ADC measurement of the renal parenchyma.

Among the control group (those patients having a focal renal lesion but with normal renal function), three circular ROIs were placed on the normal kidney parenchyma, contra-lateral to the kidney showing the focal renal lesion, each with $1 \mathrm{~cm}$ surface area, without predilection for the renal cortex or the medulla, they were located: One in the upper renal zone, one in the mid renal zone, and one on the lower zone with the mean value of the three obtained values was calculated. ROI did not target renal cortex or medulla separately because it is difficult to accurately locate the ROI cursor on each separately $[6,16,18]$.

Among those patients with impaired renal function, the ADC value was measured for each kidney with the mean ADC value of each kidney is calculated then the mean ADC value of the two kidneys is calculated. The mean ADC value and standard deviation were calculated for each obtained ROI.

Finally, the ADC mean value of each patient having clinically proved renal dysfunction was compared with that ADC in the randomly selected control group having normal kidney function tests (Fig. 1).

\section{Statistical analysis:}

Using the Statistical Package for the Social Sciences (SPSS) version 24, all patients data were entered. The comparison between quantitative variables was made using Mann-Whitney tests and the non-parametric Kruskal-Wallis. Using Spearman correlation coefficient, the correlation between quantitative variables was done. ROC curve was constructed with area under the curve analysis performed to detect best cut-off value of ADC between kidneys dysfunction and volunteers. 


\section{Results}

\section{Patient characteristics:}

The study included 44 patients having renal dysfunction (14 men, 30 women, with the mean age of 40 years), of whom 30 patients had CKD ( 8 men, 22 women, with the mean age of 39 years) and 14 have recently discovered renal dysfunction.

Of these 30 patients, 8 patients had diabetes mellitus, 8 had hypertension, 8 had systemic lupus erythematosus (SLE), 2 with renal artery stenosis and 4 had no clinical data to explain that renal dysfunction.

\section{$A D C$ values and the renal function serum markers:}

For all the volunteers, no difference could be observed on the DW images between the renal cortex and medulla and there was no significant difference in the ADC values between the right and left kidneys which ranged between $2.25 \times 10$ ${ }^{3} \mathrm{~mm} / \mathrm{s}$ and $2.32 \times 10-{ }^{3} \mathrm{~mm} / \mathrm{s}$.

As serum creatinine increase the ADC values of the renal parenchyma decrease, so we found that there was an inverse relationship between the serum creatinine level and the measured ADC values of the renal parenchyma (Pearson correlation coefficient $r=-.947, p=0.001$ ) (Fig. 2).

Among the study group with impaired renal function, significant linear correlation was detected between the renal parenchymal eGFR and the measured ADC values $(r$ 0.778725; $p=0.002)$ (Fig. 3). ROC-curve was done for differentiating between the ADC values of the normal renal parenchyma and the ADC values of kidneys with parenchymal disease. For identification of renal impairment AUC (area under curve) was -0.836 , sensitivity $100 \%$ and $p$-value 0.008 . In these patients with renal impairment, the mean ADC value of their renal parenchyma was significantly lower than the mean ADC value of those control group having normal kidney function which was $(1.69 \times 10-$ $3 \mathrm{~mm} 2 / \mathrm{s}$ versus $2.29 \times 10-\mathrm{mm}^{2} / \mathrm{s}$ ) respectively with the $p$-value of 0.007 .

For cut-off ADC value of $2.0335 \times 10-{ }^{3} \mathrm{~mm}^{2} / \mathrm{s}$, sensitivity was $100 \%$, specificity was $63.3 \%$ and confidence interval $(0.665,1000)$. So, ADC below $2.0335 \times 10-{ }^{3} \mathrm{~mm}^{2} / \mathrm{s}$ is seen only in the patients with renal impairment and ADC above 2.0335x10${ }^{3} \mathrm{~mm} / \mathrm{s}$ is seen in the patients with normal kidney function.

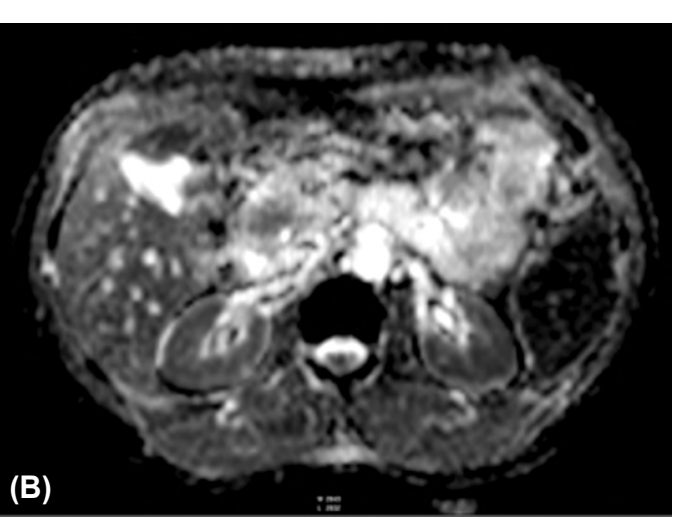

Fig. (1): (A,B) ADC MRI images (A) A CKD patient showing restricted diffusion within both kidneys with the mean ADC value of $1.772\left(\times 10 \mathrm{~mm}^{2} / \mathrm{s}\right)$. (B) Show no restriction of diffusion in a patient with normal renal function and the mean ADC value was $2.241\left(\times 10^{-3} \mathrm{~mm}^{2} / \mathrm{s}\right)$.

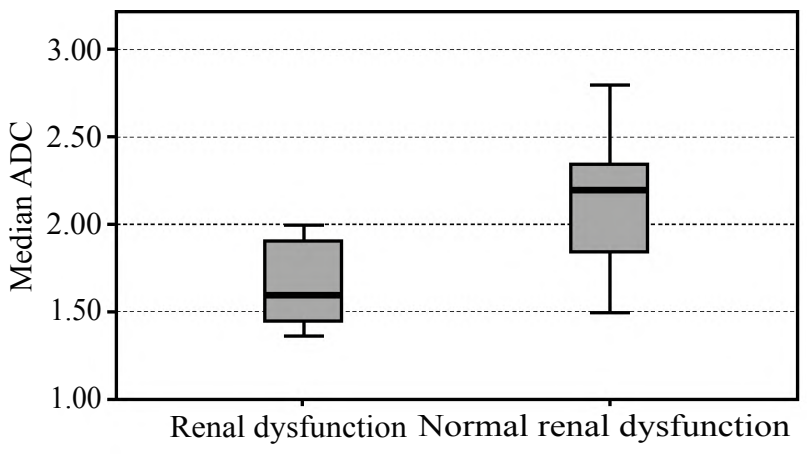

Fig. (2): Box and whisker diagram: For the ADC values of the renal parenchyma of the patients with renal impairment and those having normal kidney functions.

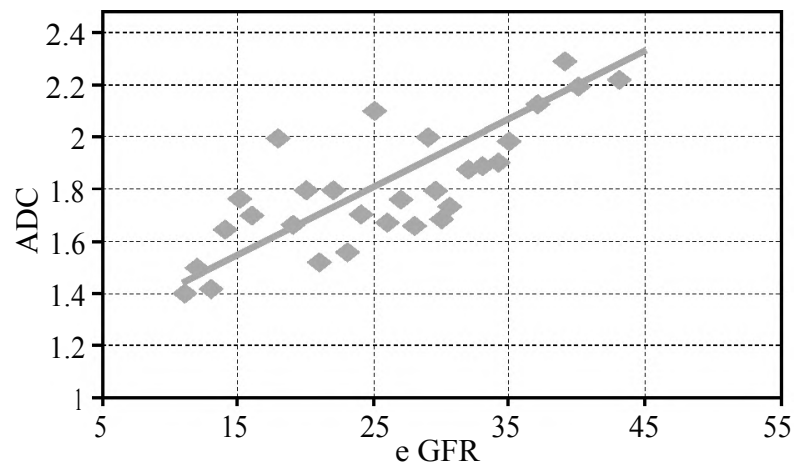

Fig. (3): Scatter plot curve: Showing a linear correlation between the eGFR and the calculated renal parenchymal ADC of those patients with renal dysfunction. 

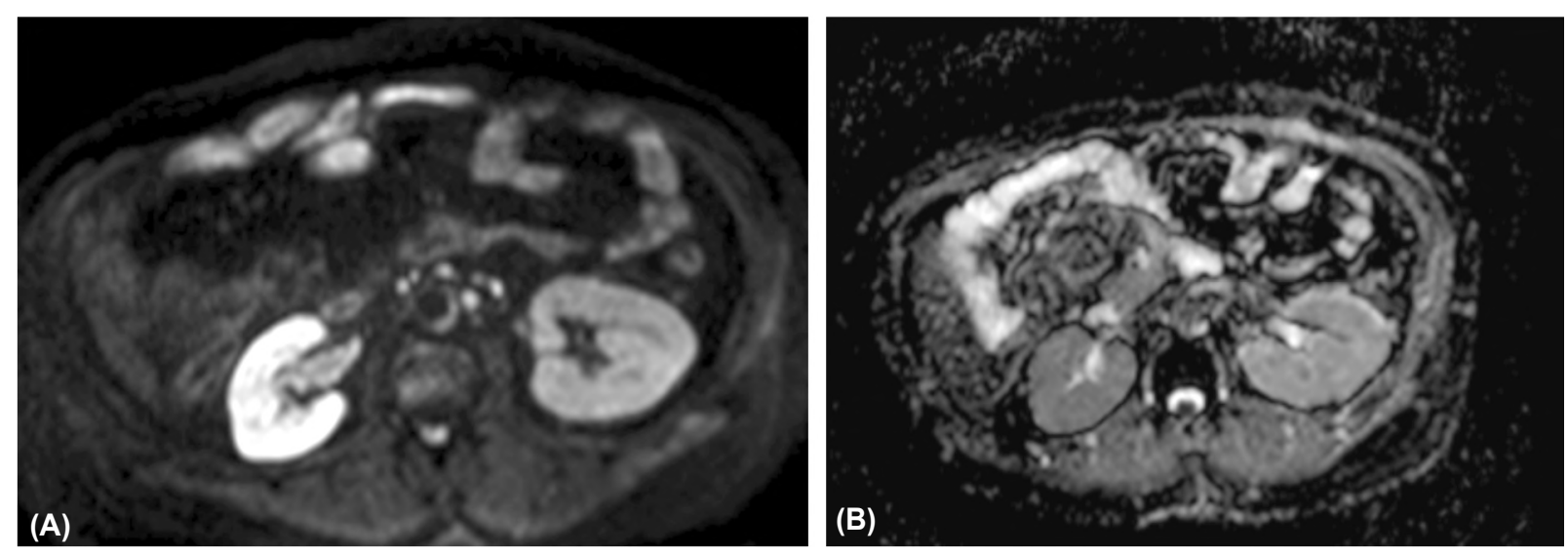

Fig. (4): A Dw image in a patient with a recently discovered kidney dysfunction having a right showing restricted diffusion ${ }_{-3}$ within the right kidney with different ADC values in B being $1.89\left(\mathrm{x}_{10}^{-3} \mathrm{~mm}^{2} / \mathrm{s}\right)$ in the right kidney versus $2.2(\mathrm{x} 10$ $\mathrm{mm}^{2} / \mathrm{s}$ ) in the left kidney.

\section{Discussion}

Renal impairment can be evaluated and monitored by various laboratory tests like Blood urea, Serum creatinine, and the estimated glomerular filtration rate (eGFR). Radiological modalities like Ultrasonography (USG) and CT that can provide good morphological information but with limited functional information beside being operator dependent in case of USG and carrying the risk of exposure to radiation in case of $\mathrm{CT}$ with probability of using iodinated contrast.

MRI study can have potential role in the renal function evaluation without radiation exposure to the patients and is capable of showing the renal structure and evaluating the renal function using the blood oxygen level-dependent (BOLD) imaging, diffusion-weighted imaging (DWI) [4]. DWMRI can be a non-invasive tool to distinguish different tissues depending on the water molecules Brownian movement within, with the apparent diffusion coefficient (ADC) can be a quantitative measure estimated from the DW imaging, which involves the effects of water diffusion and the capillary perfusion.

Numerous studies have attempted to estimate the value of DW-MRI in the characterization of the renal parenchymal disease, [7,12-16]. With low levels of b-values, the values of the ADC can be affected by both the diffusion and perfusion. With high $b$-values only, the perfusion effect can be greatly reduced to be insignificant, and then the ADC value represents a real diffusion.

Till now, the $b$-value optimal level for diffusion weighted imaging has not been specified. Some authers recommended to be higher than $400 \mathrm{~s} / \mathrm{mm}^{2}$ to minimize "T2 shine-through" and minimize perfusion effects [13]. In the same time, higher bvalue can lead to a lower signal-to-noise ratio (SNR). In our study, the $b$-values were set to be 0 and $500 \mathrm{~s} / \mathrm{mm}^{2}$.

With higher $b$-values, the worse the resolution of the obtained images, making the discrimination between the renal cortex and medulla difficult and consequently the ROIs can not be precisely located. So, we could not estimate the ADC values of the renal cortex and the renal medulla on a separate basis and the ROI cursors were put over the upper, mid and lower zones of the renal parenchyma at the mesorenal region, as described by Fukuda et al., 2000 [17], that recommended that the ADC values within the central renal region is less affected by the renal perfusion.

It is a fact that the end result of any cause of chronic renal failure, like interstitial fibrosis, tubular atrophy, and glomerulo-sclerosis, is significant restriction of the water free movement in the extracellular space that produces reduction in the ADC values of kidneys of patients with CKD. A significant inverse correlation was encountered between $\mathrm{S} \mathrm{Cr} / \mathrm{BU}$ levels and the measured ADC values of renal parenchyma.

Additionally, a significant linear correlation was detected between the eGFR in patients with CKD and the renal parenchymal ADC values. We obtained that the mean ADC value of $1.68 \times 10$ ${ }^{3} \mathrm{~mm} / \mathrm{s}$ in chronic renal failure patients was significantly lower than ADC value of the healthy Kidneys $\left(2.28 \times 10-\mathrm{mm}^{2} / \mathrm{s}\right)$ that was going with previous studies by Yoshikawa et al., [7], Namimoto et al., [12] and Xu et al., [15] . 
No significant correlation between the ADC values and the eGFR was found by Toya et al., [16]. There was no significant ADC values difference between the right and left kidneys except in a case of unilateral renal artery stenosis $(p>0.05)$ (Fig. 4). The small ADC values in such patients with renal parenchymal disease can be secondary to reduced parenchymal perfusion and reduced water diffusion through the tough renal parenchyma.

Interstitial fibrosis, renal tubular fibrosis and glomerulo-sclerosis can significantly limit the free notion of the extra and the intracellular water molecules, resulting in lower values of ADC. The values of ADC below $2.0 \times 10^{3} \mathrm{~mm}^{2} / \mathrm{s}$ were seen only in patients with renal dysfunction and above $2.4 \times 10 \mathrm{~mm} / \mathrm{s}$ were not seen in patients with renal dysfunction. A relative limitation to our study, is we estimated the values of the ADC in the patients having normal kidney function, who had additionally focal renal lesions, as a control group. Special care was taken to avoid those focal renal parenchymal lesions ADC, using the opposite kidney for ADC evaluation.

With that inverse correlation between the calculated renal parenchymal ADC values and the kidney laboratory markers in addition to that positive correlation with eGFR, we assume that measuring the renal parenchymal ADC values can be practically used to estimate and monitor renal dysfunction. Using a ADC baseline value can enable non-invasive monitoring of the progression of renal parenchymal disease with no radiation exposure or contrast material however, the disadvantages can be the MRI availability and cost.

We should announce that DW-MRI cannot totally substitute the other renal dysfunction monitoring modalities like serum markers or renal scintigraphy but it can be an additional tool, which can be incorporated within the basic MRI protocols to provide an additional functional information with insignificant prolongation of the examination time.

This obtained functional information using DWI, with the provided renal and pelvi-calyceal system (MR urography) morphological information and renal vasculature data using MR angiography, can make MRI a single modality for total comprehensive renal evaluation.

\section{References}

1- AGARWAL S.K. and SRIVASTAVA R.K.: Chronic kidney disease in India: Challenges and solutions. Nephron. Clin. Pract., 111: c197-203, 2009.
2- BAUER J.H., BROOKS C.S. and BURCH R.N.: Clinical appraisal of creatinine clearance as a measurement of glomerular filtration rate. Am. J. Kidney. Dis., 2: 337-46, 1982.

3- PRIGENT A.: Monitoring renal function and limitations of renal function tests. Semin. Nucl. Med., 38: 32-46, 2008.

4- CHANDARANA H. and LEE V.S.: Renal functional MRI: Are we ready for clinical application? AJR. Am. J. Roentgenol., 192: 1550-7, 2009.

5- SQUILLACI E., MANENTI G., DI STEFANO F., MIANO R., STRIGARI L. and SIMONETTI G.: Diffusion weighted MR imaging in the evaluation of renal tumours. J. Exp. Clin. Cancer. Res., 23: 39-45, 2004.

6- COVA M., SQUILLACI E., STACUL F., MANENTI G., GAVA S., SIMONETTI G., et al.: Diffusion weighted MRI in the evaluation of renal lesions: Preliminary results. Br. J. Radiol., 77: 851-7, 2004.

7- YOSHIKAWA T., KAWAMITSU H., MITCHELL D.G., OHNO Y., KU Y., SEO Y., et al.: ADC measurement of abdominal organs and lesions using parallel imaging technique. AJR. Am. J. Roentgenol., 187: 1521-30, 2006.

8- ZHANG J., TEHRANI Y.M., WANG L., ISHILL N.M., SCHWARTZ L.H. and HRICAK H.: Renal masses: Characterization with diffusion-weighted MR imaging_A preliminary experience. Radiology, 247: 458-64, 2008.

9- TAOULI B., THAKUR R., MANNELLI L., BABB J.S., KIM S., HECHT E.M., et al.: Renal lesions: Characterization with diffusion-weighted imaging versus contrast enhanced MR imaging. Radiology, 251: 398-407, 2009.

10- KILICKESMEZ O., INCI E., ATILLA S., TASDELEN N., YETIMOGLU B., YENCILEK F., et al.: Diffusionweighted imaging of the renal and adrenal lesions. J. Comput. Assist. Tomogr., 33: 828-33, 2009.

11- SANDRASEGARAN K., SUNDARAM C.P., RAMASWAMY R., AKISIK F.M., RYDBERG M.R., LIN C, et al.: Usefulness of diffusion-weighted imaging in the evaluation of renal masses. AJR. Am. J. Roentgenol., 194: 438-45, 2010.

12- NAMIMOTO T., YAMASHITA Y., MITSUZAKI K., NAKAYAMA Y., TANG Y. and TAKAHASHI M.: Measurement of the apparent diffusion coefficient in diffuse renal disease by diffusion-weighted echo-planar MR imaging. J. Magn. Reson. Imaging, 9: 832-37, 1999.

13- THOENY H.C., DE KEYZER F., OYEN R.H. and PEETERS R.R.: Diffusion-weighted MR imaging of kidneys in healthy volunteers and patients with parenchymal diseases-initial experience. Radiology, 235: 911-7.

14- XU Y., WANG X. and JIANG X.: Relationship between the renal apparent diffusion coefficient and glomerular filtration rate: Preliminary experience. J. Magn. Reson. Imaging, 26: 678-81, 2007.

15- XU X., FANG W., LING H., CHAI W. and CHEN K. Diffusion-weighted MR imaging of kidneys in patients with chronic kidney disease: Initial. study. Eur. Radiol., 20: 978-83, 2010.

16- TOYA R., NAGANAWA S., KAWAI H. and IKEDA M.: Correlation between estimated glomerular filtration rate (eGFR) and apparent diffusion coefficient (ADC) values of the kidneys. Magn. Reson. Med. Sci., 9: 59-64, 2010. 
17- FUKUDA Y., OHASHI I., HANAFUSA K., NAKAGAWA T., OHTANI S., ANNAKA Y., et a.l.: Anisotropic diffusion in kidney: Apparent diffusion coefficient measurements for clinical use. J. Magn. Reson. Imaging, 11: 156-60, 2000 .
18- VERSWIJVEL G., VANDECAVEYE V., GELIN G., VAN-DEVENNE J., GRIETEN M. HORVATH M., et al.: Diff-usion-weighted MR imaging in the evaluation of renal infection: Preliminary results. JBR-BTR, 85 : 100-3, 2002.

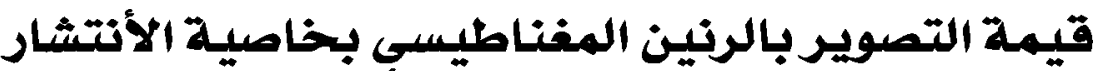 كمؤشر غير داخلى لتقييه الأعتئلانل الكلوى}

الخلفية: مرضى الكلى المزمن هو مشكلة صحية واسعة الأنتشار. الأختبارات المعملية والإشعاعية المختلفةمفيدة في تقييم التفيرات

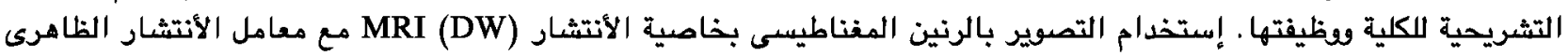

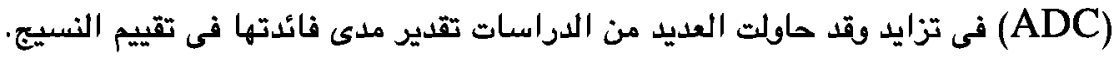

الهدف: تقييم العلاقة بين الأختبارات المعملية للكلى وقيم معامل الأنتشار الظاهرى (MR-ADC) للنسيج الكلوى.

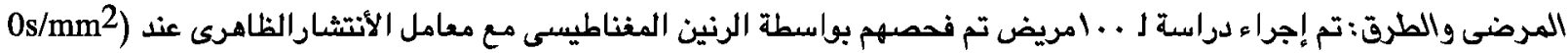

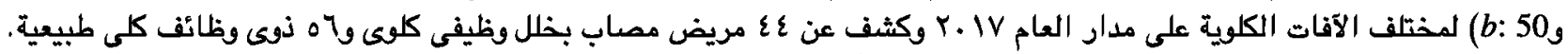

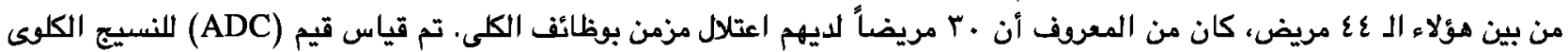
لكل كلية ومقارنتها مع تلك القيم من الكلى الطبيعية. تم إنشاء منحنى (ROC) لتحديد قيمة (cur off value ADC).

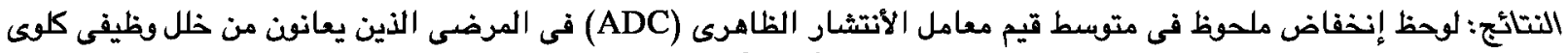

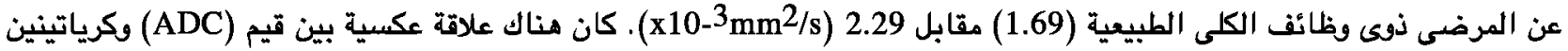

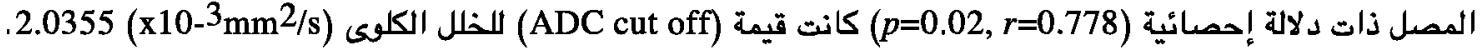

الخلاصة: يمكن أن قياس قيم معامل الأنتشار الظاهرى MRI ADC علامة مفيدة للتنبؤ بمرض النسيج الكلوى. 